\title{
First feeding success with two types of prey by the Central American cichlid fish, Cichlasoma managuense (Pisces, Cichlidae): morphology versus behavior
}

\author{
Axel Meyer \\ Department of Zoology and Museum of Vertebrate Zoology, University of California, Berkeley, CA 94720 , \\ U.S.A.
}

Keywords: Capture rate, Capture efficiency, Handling effort, Persistence in hunting

Konstanzer Online-Publikations-System (KOPS)

URL: http://www.ub.uni-konstanz.de/kops/volltexte/2007/3687/

URN: http://nbn-resolving.de/urn:nbn:de:bsz:352-opus-36873

\section{Synopsis}

The behavioral and morphological correlates of differential capture success at first feeding of the cichlid fish Cichlasoma managuense were investigated. Capture efficiency with nauplii of Artemia salina was $69 \%$ compared with only $6 \%$ with Daphnia. These drastic differences are attributed largely to the different morphology and behavior of the prey that may have produced behavioral changes in the fish. Daphnia is more evasive and harder to handle than Artemia as reflected in the significantly higher number of missed capture attempts and in spit-outs, a measure of handling effort. Fish hunting Artemia had a high capture rate when they made many attempts. By contrast, fish hunting Daphnia were successful when they handled the prey persistently, made many spit outs and many attempts. Large behavioral variation was observed and may be the substrate for later food specialization. In contrast to previous studies, morphological variation in the predators and prey was kept low; no measured morphological trait of the predators explained a significant portion of the variation in capture rate. The behavioral differences among the predators in each group alone significantly explain the variation in capture rate. The developmental stage of the fish and the behavior of the prey need to be considered when comparing the capture efficiency between species.

\section{Introduction}

The study of the development of feeding behavior of fishes is important because early mortality mostly from predation and starvation influences recruitment (e.g. Hunter 1971). Therefore first feeding success, especially of commercially important fish species, is of special interest (e.g. Braum 1967, Blaxter \& Staines 1972, Rosenthal \& Hempel 1970, Hunter 1971). Many authors have demonstrated that the behavioral sequence of first feeding typically involves visual fixation of the prey item followed by the assumption of stereoscopic vision. Upon fixation, most larvae assume a S-posture and then lunge forward, attempting to capture the prey. If the prey notices the fish during fixation, it might attempt to escape. Then the fish omits the rest of the behavioral sequence of prey capture.

Not all fish have the same behavioral sequence of prey capture at first feeding. For example, some species never S-posture before lunging (Rosenthal 1966: Solea solea). The predation success of many species during first feeding ranges from 1-10\% (Riley 1966: Pleuronectes platessa, Blaxter 1962, Rosenthal 1969: Clupea harengus, Rosenthal 1966: Solea solea, Fonds 1970: Pomatochistus spp.), to 40-50\% (Chitty 1981: Anchoa mitchilli, A. lamprotaenia) and rarely even 100\% (Rosenthal 1970: Belone belone).

The type of prey greatly influences first capture 


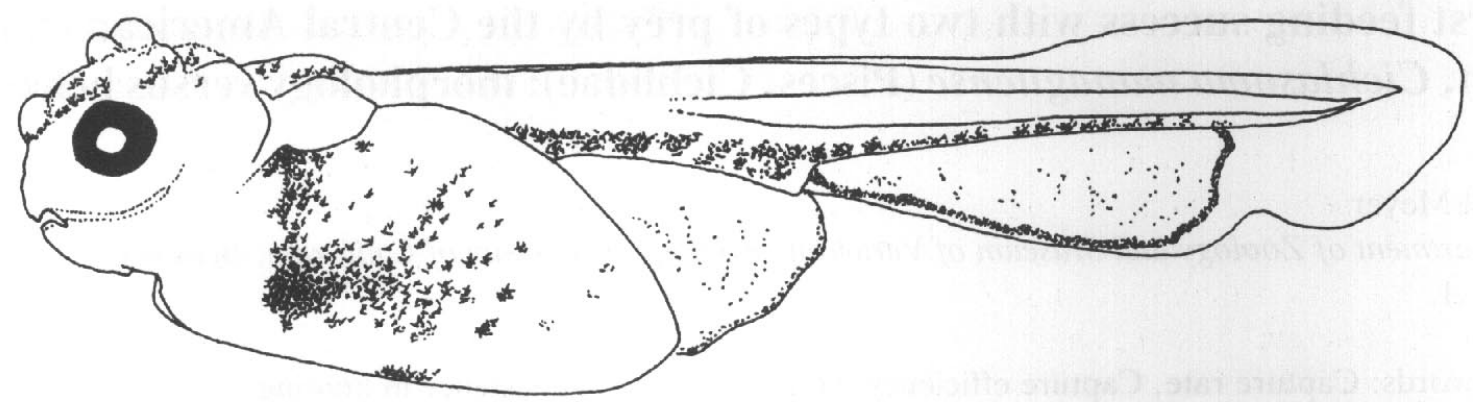

Fig. 1. Cichlasoma manguense shortly after hatching. TL $6.3 \mathrm{~mm}$.

success. After a few experiences with one type of prey, individual Clupea harengus larva, given a choice between familiar and novel prey, feed on one type only; apparently they respond preferentially to a particular type of prey that these individuals can capture readily. Novel prey are generally not taken to the same extent as familiar prey (Rosenthal 1969, Bergmann 1971, Bryan 1973, Meyer 1986). Bryan \& Larkin (1972) suggested a similar mechanism for the food specialization of individual food-experienced rainbow trout, Salmo gairdneri. Nevertheless, no detailed study tested what determines differential capture success with different prey items at the onset of feeding on external food sources in fish.

Young Cichlasoma managuense are guarded and defended by their parents for about six weeks (McKaye \& Barlow 1976). During this time, the young fish start feeding exogenously and develop considerably (Fig. 1, 2). Preliminary laboratory observations indicate that at the onset of external feeding they feed indiscriminately and with varying success on different prey items. I investigated the prey catching ability of food-naive young of $\mathrm{Ci}$ chlasoma managuense with two different types of prey when first feeding on external food sources. This study measured the differences in behavioral and morphological traits of predator and prey associated with capture rate with two types of prey, and considered possible causes of variation in capture success.

\section{Materials and methods}

The fish were laboratory bred siblings from one spawning event to minimize genetical variation between individuals. Upon completion of the free embryo phase (Balon 1985), a total of 48 young, about $9.1 \mathrm{~mm}$ in total length (Fig. 2, Table 1), were randomly assigned to be fed on Artemia or Daphnia and placed singly into separate observation chambers. The observation chambers, measured $10 \times 10 \times 10 \mathrm{~cm}(11)$ and were visually separated from each other. Illumination was provided by $20 \mathrm{~W}$ fluorescent light bulbs $20 \mathrm{~cm}$ above and be-

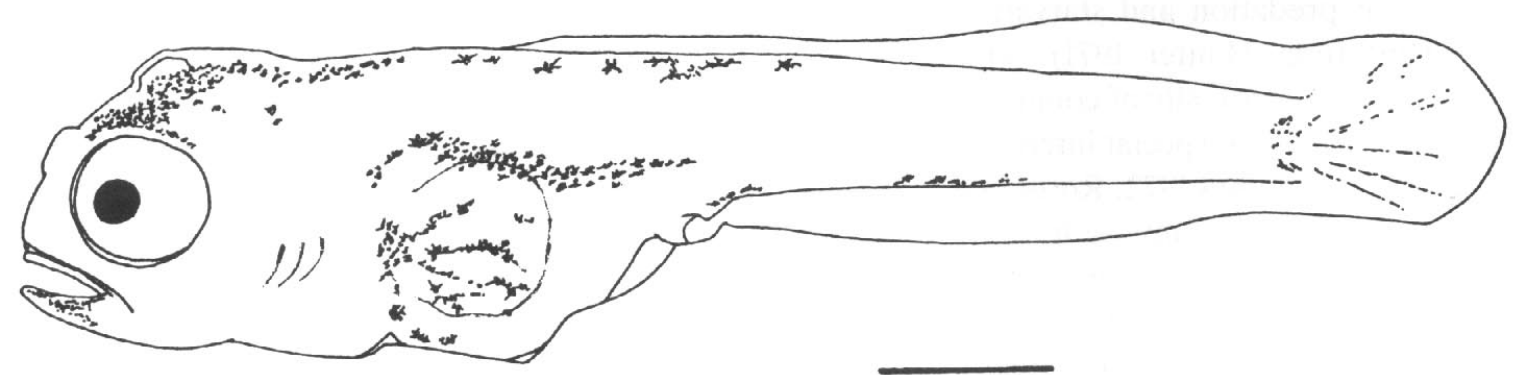

Fig. 2. Cichlasoma managuense at the onset of feeding on external food sources. The support of the median fins is not developed yet. The bar represents $1 \mathrm{~mm}$. 
hind the chambers. The temperature was kept at $26^{\circ} \mathrm{C} \pm 1^{\circ} \mathrm{C}$.

Each fish was tested only once, contributing only one datum to the analysis. The fish had no prior feeding experience with external food sources. Four fish never attempted to prey on Daphnia during the observation time and one fish did not prey on Artemia. One Daphnia-group fish died during acclimation. These fish were excluded from the analysis which resulted in unequal sample sizes between the groups ( 23 fish in the Artemia group and 19 in the Daphnia group). No morphological data were collected from 11 of the 23 fish in the Artemia group. These missing data reduced the sample size in some of the later analyses.

The fish were acclimated $24 \mathrm{~h}$, without food, in the experimental chambers with a $12: 12 \mathrm{~h}$ light:dark cycle. Acclimation (up to $24 \mathrm{~h}$ ) significantly calms the behavior of the fish (unpublished observations). Each fish was offered about 150 individuals of its assigned prey type, either Artemia or Daphnia, and its behavior was immediately observed for $7 \mathrm{~min}$. The sequence of Artemia and Daphnia experiments was randomized throughout the whole experimental procedure.

Immediately after the observation the fish was removed from the observation chamber, deeply anesthetized and fixed in 10\% buffered formalin. No prey items were spit-out or lost from the fish's mouth during this procedure. Later the fish were measured and the stomach contents examined. The prey were nauplii of Artemia salina and Daphnia sp.. Nauplii of Artemia salina have been used in most studies of the first feeding of fish (e.g. Rosenthal 1969). The Daphnia were sieved repeatedly to obtain a prey of comparable size to the nauplii of Artemia salina ( 0.2 to $0.4 \mathrm{~mm}$ in diameter).

During the observations the following behavioral measures were recorded:

Latency - the time elapsed between the introduction of the prey and the first attempt of the fish to capture a prey item, measured in sec.

Miss - a completed but unsuccessful attempt to capture a prey item. The fish might have aimed in the wrong direction or did not lunge far enough, or the prey evaded the attack, all of which resulted in a missed capture-attempt.

Spit-out-a prey capture followed by spitting out or losing the prey from the predator's mouth shortly after capture. It was not possible to distinguish between a purposeful and an involuntarily release of the prey. The number of spit-outs was interpreted as an indication of the degree of difficulty in handling prey.

Table 1. Analysis of variance comparing the variables of both groups of young. The sample sizes were 12 for the morphological variables and 23 for the behavioral variables of the Artemia group and 19 for all variables of the Daphnia group (except handling effort). These sample sizes gave 30 and 41 degrees of freedom respectively for the One-Way-ANOVAs. In the ANOVA testing for differences in handling effort there were 9 cases missing in the Daphnia group due to the way handling effort was calculated; this resulted in 32 degrees of freedom. The ANCOVAs with weight as covariate yielded the same results, except for the variable 'attempts'.

\begin{tabular}{|c|c|c|c|c|c|c|}
\hline & \multicolumn{2}{|c|}{ Artemia } & \multicolumn{4}{|c|}{ Daphnia } \\
\hline & Mean & $\mathrm{SD}$ & Mean & $\mathrm{SD}$ & F-ratio & $\mathrm{p}$-value \\
\hline total length (mm) & 9.17 & 0.145 & 9.16 & 0.156 & 0.04 & $>0.05$ \\
\hline weight $(\mathrm{g}) \times 1000$ & 4.9 & 0.0007 & 5.48 & 0.0007 & 4.17 & $=0.05$ \\
\hline eye diameter $(\mathrm{mm})$ & 1.09 & 0.0359 & 1.05 & 0.1120 & 4.15 & $>0.05$ \\
\hline capture rate & 10.0 & 6.53 & 1.05 & 1.39 & 34.3 & $<0.000$ \\
\hline capture efficiency & 0.689 & 0.2272 & 0.058 & 0.0715 & 68.5 & $<0.000$ \\
\hline latency $(\mathrm{sec})$ & 10.0 & 5.50 & 11.6 & 6.90 & 0.07 & $>0.05$ \\
\hline attempts & 14.6 & 8.80 & 14.5 & 8.97 & 0.00 & $>0.05$ \\
\hline nonprey & 2.0 & 2.81 & 0.89 & 1.82 & 2.17 & $>0.05$ \\
\hline misses & 0.73 & 1.36 & 2.89 & 2.98 & 9.65 & $<0.000$ \\
\hline spit-outs & 0.130 & 0.344 & 4.32 & 4.23 & 22.5 & $<0.000$ \\
\hline handling effort & 0.051 & 0.146 & 3.98 & 4.30 & 19.9 & $<0.000$ \\
\hline
\end{tabular}


Prey capture - a capture attempt followed by swallowing the prey. It was usually not possible to distinguish between capture of a prey and ingestion of a nonprey item. In the data analysis prey capture was replaced by the actual counts of prey and nonprey items in the stomach.

The following counts and measurements were taken after the observations:

Total length-distance from the tip of the upper jaw to the end of the caudal fin, measured under a dissecting microscope.

Eye diameter - was measured as the distance between the outer margins of the eyeball.

Weight - wet weight including ingested prey.

Capture rate - the number of prey and nonprey items counted in the stomach. The number of prey caught during the observation time is the capture rate, used as the dependent variable in later analyses as the parsimonious approach.

Capture efficiency - the capture rate as a percentage of attempts to allow comparisons of the firstfeeding success with other species. The ratio of capture rate to attempts has sometimes been defined as capture-success but I believe that capture efficiency is a more appropriate term for this ratio of return (capture rate) to energy expenditure (attempts). The terms capture rate and capture efficiency distinguish between rate (units:time) and efficiency (units:energy, measured in attempts) better than the term capture-success.

Nonprey - were items such as stones, eggshells of Artemia salina, and other particulate debris.

Handling effort - the ratio of spit-outs to capture rate, gives an indication of the difficulty of prey handling.

\section{Statistical methods}

Comparisons between the two groups were made using One-Way-ANOVAs $(\mathrm{k}=2$, T-tests $)$. The fish were taken at random from the brood and the two groups did not have significantly different weights $(P=0.0506)$. Therefore I report the results of the One-Way-ANOVAs in Table 1. Additionally however, I conducted analyses of covariance with weight as the covariate, as a more conservative test. Prior to the ANCOVA I tested for nor- mality of the data and 'homogeneity of the slopes' (Sokal \& Rholf 1981, Dixon \& Massey 1983). In all tests, except in the variable 'attempts', both analyses yielded the same results (see Table 1). The sample sizes were 42 for the comparisons of the behavioral data and 31 for the morphological data. To explain within-group variability and to depict the relative importance of the behavioral and morphological predictor variables, multiple stepwize regression analyses were used. The data from the Artemia and the Daphnia groups were transformed, when necessary, to meet the assumptions of the statistical tests.

\section{Results}

\section{Morphology}

The fish in both groups did not differ from each other with respect to morphology but the fish of the Daphnia group were somewhat heavier $(\mathrm{p}=0.05$, Table 1). This weight included the captured prey because it was not possible to weigh the tiny, fragile fish before the experiment (Fig. 2) nor was it feasible to weigh the fish accurately after the removal of the prey from its stomach because this procedure required extensive shredding of the fish's body. A regression of the weight (including the prey) versus the capture rate revealed no significant relationship (regression analysis, $\mathrm{F}=3.98, \mathrm{df}=30, \mathrm{r}=$ $-0.3472, p>0.05$, notice the negative correlation coefficient). The prey's weight did not contribute perceptibly to the predator's weight or smaller fish had somewhat higher capture rates.

\section{Behavior}

Cichlasoma managuense goes through nearly the same behavioral sequence as other species at first feeding. However, the cichlid young do not assume the S-posture with every capture-attempt as has been discribed in Clupea harengus (Rosenthal 1969) and they attempt to capture a particular prey item more consistently.

Without the use of high-speed cinematography it was not possible to determine whether the fish 
assumed the S-posture to varying degrees. The impression, however, was that the fish stayed longer in S-posture and with a greater amplitude when hunting the more evasive prey, Daphnia, but the amplitude did not appear as large as reported in other species (e.g. Rosenthal 1969).

The development of the ability to distinguish between palatable and unpalatable prey items is critical (Dill 1983, Meyer 1986). At first feeding, young of Cichlasoma managuense do not discriminate well. They not only snap at prey items, but also attempt to feed on inert objects such as detritus, airbubbles, and eggshells of Artemia salina. I also found tiny stones in the stomachs of fish at first feeding. However the fish snap more readily at moving objects than nonmoving ones.

The capture rate with Artemia salina as prey was significantly higher than with Daphnia (One-WayANOVA, $\mathrm{F}=34.32$, $\mathrm{df}=41, \mathrm{p}<0.0001$, Table 1). The fish in the Antemia group had on average about 10 prey items in their stomachs, while those in the Daphnia group had one prey item, with considerable individual variation (coefficient of variation (CV): Artemia group 65\%, Daphnia group $132 \%$ ). The reduction of prey density during the brief observation period was not sufficient to affect prey capture.

Capture efficiency (slopes in Fig. 3, 4) was also significantly higher in the Artemia than in the Daphnia group (One-Way-ANOVA, $\mathrm{F}=68.51$, $\mathrm{df}=41, \mathrm{p}<0.0001$, Table $1, \mathrm{CV}: 33 \%, 123 \%)$. Artemia were caught in almost $70 \%$ of all attempts, but only $6 \%$ of all attempts to capture Daphnia ended successfully. Both groups of fish had equally long latencies of about 10 seconds $(\mathrm{F}=0.707, \mathrm{df}=$ $41, \mathrm{p}>0.05$, Table 1, CV: $55 \%, 59 \%$ ). The number of attempts, the sum of prey captures (from the behavioral observations) plus misses plus spit-outs, was not different in the two groups (One-WayANOVA, $\mathrm{F}=0.00, \mathrm{df}=41, \mathrm{p}>0.05$, Table $1, \mathrm{CV}$ : $60 \%, 62 \%$, but see caption of Table 1). Both groups tried with equal persistance. The number of nonprey items found in the stomachs did not differ between the Artemia and Daphnia groups (OneWay-ANOVA, $\mathrm{F}=2.17, \mathrm{df}=41, \mathrm{p}>0.05$, Table 1 , CV: $140 \%, 204 \%$ ). The variation was large in both groups hinting at the large individuality in the fish's

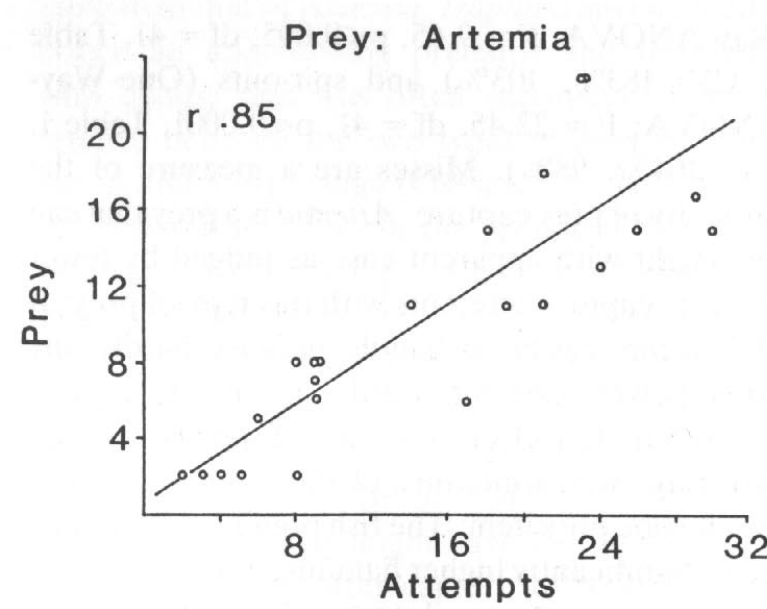

Fig. 3. X-Y-plot of attempts versus capture rate with Artemia as prey. The regression line has the formula: capture rate $=0.77+$ $0.63 \times$ attempts. $72 \%$ of the variation in the variable capture rate is explained by the number of attempts made by the fish (regression analysis, $\mathrm{F}=55.24, \mathrm{df}=22, \mathrm{p}<0.001, \mathrm{r}=0.85$. $\mathrm{p}<0.05)$. The slopes in Figure 3 and 4 are the capture efficiency.

responses to the available prey. Dietary specialization may result from such large behavioral variation at the onset of feeding.

Daphnia were more evasive hence harder to catch and have a harder carapace. This was revealed by the difference between the groups in misses and spit-outs. The fish preying on Daphnia had a significantly higher number of misses (One-

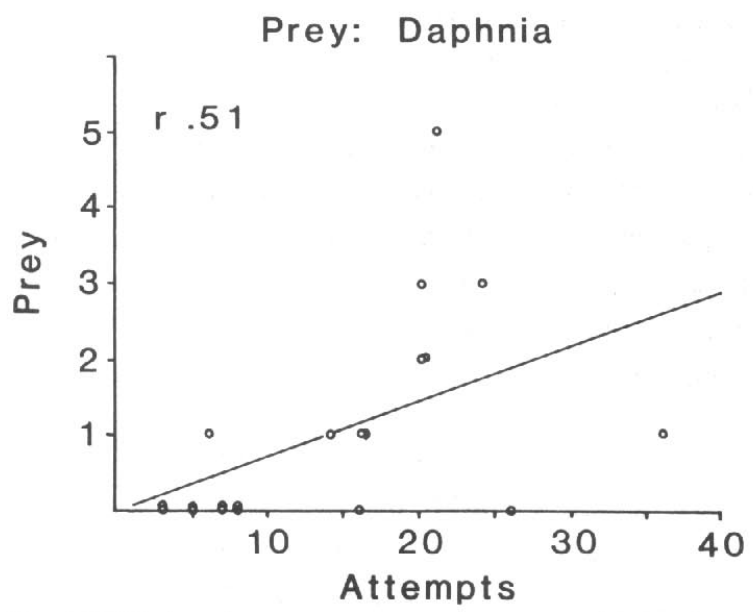

Fig. 4. X-Y-plot of attempts versus capture rate with Daphnia as prey. The regression line has the formula: capture rate $=$ $-0.095+0.079 \times$ attempts. The regression is significant (regression analysis, $\mathrm{F}=5.93, \mathrm{df}=18, \mathrm{r}=0.51, \mathrm{p}<0.05) .26 \%$ of the variation in capture rate is explained by the variable 'attempts'. 
Way-ANOVA, $\mathrm{F}=9.65, \mathrm{p}<0.005, \mathrm{df}=41$, Table 1, CV: $183 \%, 103 \%$ ) and spit-outs (One-WayANOVA, $\mathrm{F}=22.45, \mathrm{df}=41, \mathrm{p}<0.0001$, Table 1 , CV: $264 \%, 98 \%$ ). Misses are a measure of the difficulty of prey capture. Artemia is a prey that can be caught with apparent ease as judged by fewer 'missed' capture-attempts with this type of prey. It also seems easier to handle because hardly any Artemia were spit-out after being caught.

The handling effort, the ratio of spit-outs to capture rate, was a measure of the effort needed to handle one prey item. The fish preying on Daphnia had a significantly higher handling effort (4.0) than the fish preying on Artemia (0.05) (One-WayANOVA, $\mathrm{F}=19.9, \mathrm{df}=32, \mathrm{p}<0.0001$, Table 1$)$. The capture rate with Daphnia was so low that most fish could not subsist on this diet and would starve to death over a period of two weeks if no other prey were offered. Nonetheless, the young responded equally to the two types of prey in latency and attempts.

\section{Variation within groups of fish}

To explain the variation in capture success within a group of fish preying on one type of prey, I conducted multiple stepwise regression analyses with capture rate as dependent variable. Because the sample size in the Artemia group was reduced, only behavioral variables were used as independent variables in the multiple regression analysis for this group. However, simple linear regressions were done with the morphological variables as predictors of the capture rate, and none of these was significant. This prior test justified the exclusion of the morphological variables. In the Daphnia group all morphological and behavioral variables were used as predictor variables. The adjusted $\mathrm{R}$-squared value was used to judge when the greatest part of the variability in the dependent variable was explained.

In the case of the Artemia group, $72 \%$ of the variability in the capture success is explained alone by the variable 'attempts'. The linear regression model is: capture rate $=0.77+0.63 \times$ attempts, its slope significantly different from 0 (regression analysis, $\mathrm{F}=55.24, \mathrm{df}=22, \mathrm{r}=0.85, \mathrm{p}<0.0001$,

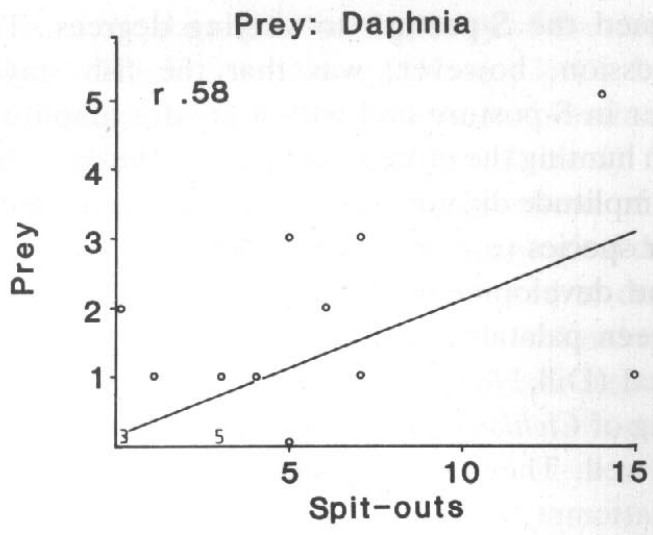

Fig. 5. X-Y-plot of spit-outs versus capture rate with Daphnia as prey. The regression is significant (regression analysis, $\mathrm{F}=8.68$, $\mathrm{df}=18, \mathrm{r}=0.58, \mathrm{p}<0.01) .34 \%$ of the variation in capture rate is explained by the variable 'spit-out'. The regression line has the formula: capture rate $=0.23+0.19 \times$ spit-outs.

Fig. 3). Fish that made many attempts had a high capture rate. The variable 'attempts' also explains a significant portion of the variability in the capture success in the Daphnia group $(\mathrm{F}=5.93, \mathrm{df}=18$, $r=0.51, p<0.05$, Fig. 4). Both groups attempted to catch prey equally often (Fig. 3,4 ), yet the slopes are significantly different $(\mathrm{F}=67.84, \mathrm{df}=38$, $\mathrm{p}<0.0001)$. The variable 'spit-outs' explains a larger portion of the variation in the dependent variable and a multiple stepwise regression analysis invoked 'spit-outs' as the only variable (Fig. 5). The linear regression model is: capture rate $=$ $0.23+0.19 \times$ spit-outs (regression analysis, $\mathrm{F}=$ 8.68 , df $=18, r=0.58, p<0.01$, Fig. 5). Fish that made many spit-outs had a high capture success.

\section{Discussion}

The ratio of prey size to fish size typically decreases with increasing size of fish which tends to increase capture efficiency. This is brought about by a number of correlated changes: absolute swimming speed and the fast-start ability increase, fin support and jaw apparatus mature, and the speed of the behavioral sequence of prey capture increases (e.g. Webb \& Corolla 1981). Visual acuity increases with 
the growth of the eye during the ontogeny of the fish (Johns 1981, O'Connell 1981, Fernald 1984). Hence the size of the eye might influence prey capture. If an indicator of strength and stamina, then weight of young should influence capture success. Capture efficiency might be positively correlated with the length and weight of the fish. However, neither size nor any other measured morphological trait of the young of Cichlasoma managuense used in this study influenced significantly the capture rate. Although the young that preyed on Daphnia were somewhat heavier, which created an unplanned but conservative bias, they had a lower capture rate and capture efficiency than the fish that preyed on Artemia.

\section{Difference in prey morphology and behavior}

Differences in morphology and behavior of the prey influenced the predators' behavior and consequently its capture efficiency. Rosenthal (1969) observed that the lunging speed of herring larvae depends on the type of prey, and the S-posture was more extreme when they attempted to prey on adult copepods than on nauplii. In contrast to most previous studies my fish could choose neither type nor size of their prey. Yet, they responded equally in latency and attempts to either type of prey.

Daphnia and Artemia differ in some crucial features which might be responsible for the observed differences in capture rate and capture efficiency. Artemia is more spindle-like while Daphnia is more oval, and Artemia is slightly redder in color. Inherent color preferences may cause differential uptake of prey (Clarke \& Sutterlin 1985). Daphnia occurs in the natural habitat of Cichlasoma managuense, Artemia salina does not.

The nauplii of Artemia resemble copepods in body shape and mode of locomotion. Artemia, although 'jumping' erratically, moves in a more continuous, predictable fashion and 'jumps' shorter distances than Daphnia. Artemia has no natural predators in its hypersaline habitat and has probably not been selected for escape behavior. Artemia does not show fast escape responses as do cladocerans. The movement of Daphnia, on the other hand, is temporally as well as spatially less predic- table than that of Artemia. Daphnia also seemed to notice an approaching predator and responded with escape that was often successful. This difference between the two types of prey in movements and morphology is believed to have created the differences between the groups of fish in the number of misses and spit-outs. The fish preying on Daphnia had more difficulty catching (misses) them than did fish hunting Artemia.

Once a prey is caught it still must be handled and swallowed. The carapace of Daphnia is hard and has a spine at its end. Because of these morphological features the fish might have had to repeatedly spit out the prey after capture to reposition and mascerate it. Fish that handled one particular prey item persistently (had a high number of spit-outs) had a higher capture rate (Fig. 5), but in repeatedly spitting out the prey, also ran the risk of losing it. Only a small number of Daphnia, however, were able to escape during the repeated spit-outs. Often the Daphnia seemed to be injured when the fish spit it out. Some fish repeatedly concentrated on one particular prey item until it was swallowed. From this I conclude that a persistently, though not necessarily 'skillfully', handling fish will be the more successful predator. This persistency may account for the higher capture efficiency of large young at first exogenous feeding, like cichlids, compared to clupeids (e.g. Hunter 1971). The fish not only caught more Artemia, but also ingested more nonprey items than when preying on Daphnia. The Artemia culture medium also contained egg shells, so they probably were accompanied by more nonprey items than were the Daphnia. This suggestion that successful capture of prey facilitates the indiscriminant uptake of nonprey merits further testing.

A first-feeding efficiency of $70 \%$ when hunting Artemia has been reported in only one other species (Rosenthal 1970) Belone belone, and those young are also large at the commencement of feeding. The high efficiency of young Cichlasoma manguense must be interpreted in light of the relatively advanced developmental state at initial exogenous feeding (Fig. 2). 


\section{Acknowledgements}

This research was performed in partial fulfillment of the requirements for the M.A. degree at the University of California at Berkeley. Thanks to George W. Barlow for advice, constructive criticism and financial support through grant HD18496 of the National Institute of Child Health and Human Development. Further support was provided through Fulbright-Fellowships from the German and the American Governments, and fellowships from the University of California. I am grateful to S. Glickman, H. Greene, W.P. Sousa and J.K. Wetterer for helpful criticism on an earlier draft, and to A. Bingham, R. Francis, J. Holder, B. Mitchell, W. Rogers, W. Sousa for their suggestions and for bearing with me. For technical assistance, I thank Y.H. Bine, M. Bisset, B. Choi, M. Leong, W.P. Sousa, P. Trex, and A. Young. Thanks also to Mr. De Bois of San Francisco for lending me a breeding pair of Cichlasoma managuense, and to W. Yamada for the drawing of the fish in Figure 1 and 2.

\section{References cited}

Balon, E.K. 1985. (ed.) Early life history of fishes: new developmental, ecological and evolutionary perspectives. Dr W. Junk Publishers, Dordrecht. 280 pp.

Bergmann, H.H. 1971. Untersuchungen zur Verhaltensentwicklung beim Segelflosser Pterophyllum scalare Cuv. Val. Z. Tierpsychol. 29: 343-388.

Blaxter, J.H.S. 1962. Herring rearing IV. Rearing beyond the yolk sac stage. Mar. Res. 1: 1-18.

Blaxter, J.H.S. \& M.E. Staines 1972. Food searching potential in marine fish larvae. pp. 467-485. In: D.J. Crisp (ed.) 4th European Marine Ecology Symposium, Cambridge University Press, Cambridge.

Braum, E. 1967. The survival of fish larvae with reference to their feeding behavior and the food supply. pp. 113-131. In: S.D. Gerking (ed.) The Biological Basis of Freshwater Fish Production, Blackwell, Oxford.

Bryan, J.E. 1973. Feeding history, parental stock, and food selection in rainbow trout. Behaviour 45: 123-153.

Bryan, J.E. \& P.A. Larkin 1972. Food specialization of individual trout. J. Fish. Res. Board Can. 29: 1615-1624.

Chitty, N. 1981. Behavioral observations of feeding larvae of bay anchovy, Anchoa mitchilli and bigeye anchovy, Anchoa lamprotaenia. Rapp. P.-v. Reun. Cons. int. Explor. Mer. 178: 320-321.
Clarke, L.A. \& A.M. Sutterlin 1985. Associative learning, short-term memory, and colour preference during first feeding by Atlantic salmon. Can. J. Zool. 63: 9-14.

Dill, L.M. 1983. Adaptive flexibility in the foraging behavior of fishes. Can. J. Fish. Aquat. Sci. 40: 398-408.

Dixon, W.J. \& F.J. Massey, Jr. 1983. Introduction to statistical analysis, 4th edition. McGraw Hill, New York. 678 pp.

Fernald, R.D. 1984. Vision and behavior in an African cichlid fish. Amer. Sci. 72: 56-65.

Fonds, M. 1970. Remark on the rearing of gobies (Pomatoschistus minutus and $P$. lozanoi) for experimental purposes. Helgoländ. wiss. Meeresunters. 20: 620-628.

Hunter, J. 1971. Feeding ecology of marine fish larvae. pp. 32-77. In: R. Lasker (ed.) Marine Fish Larvae, Morphology, Ecology, and Relation to Fisheries, University of Washington Press, Seattle.

Johns, P.R. 1981. Growth of fish retinas. Amer. Zool. 21: 447458.

McKaye K.R. \& G.W. Barlow. 1970. Competition between color morphs of the Midas cichlid Cichlasoma citrinellum, in Lake Jiloa, Nicaragua. pp. 465-475. In: T.B. Thorson (ed.) Investigations of the Ichthyofauna of Nicaraguan Lakes, University of Nebraska Press, Lincoln.

Meyer, A. 1986. Changes in behavior with increasing experience with a novel prey in fry of the Central American cichlid: Cichlasoma managuense (Teleostei: Cichlidae). Behaviour (in press).

O'Connell, C.P. 1981. Development of organ systems in the northern anchovy, Engraulis mordax, and other teleosts. Amer. Zool. 21: 429-446.

Riley, J.D. 1966. Marine fish culture in Britain. 7. Plaice (Pleuronectes platessa L.). Post larval feeding on Artemia salina $\mathrm{L}$. nauplii and the effects of varying feeding levels. J. Cons. int. Explor. Mer. 30: 204-221.

Rosenthal, H. 1966. Beobachtungen über das Verhalten der Seezungenbrut. Helgoländ. wiss. Meeresunters. 13: 213-228.

Rosenthal, H. 1969. Untersuchungen über das Beutefangverhalten bei Larven des Herings Clupea harengus. Marine Biology 3: 208-221.

Rosenthal, H. 1970. Anfütterung und Wachstum des Hornhechtes Belone belone. Helgoländ. wiss. Meeresunters. 21: 320-322.

Rosenthal, H. \& G. Hempel. 1970. Experimental studies in feeding and food requirements of herring larvae (Clupea harengus L.). pp. 344-364. In: J.H. Steele (ed.) Marine food chains, Oliver and Boyd, Edinburgh.

Sokal, R.R. \& F.J. Rohlf 1981. Biometry, 2nd edition. Freeman, New York. 859 pp.

Webb, P.W. \& R.T. Corolla. 1981. Burst swimming performance of northern anchovy, Engraulis mordax, larvae. U.S. Fish. Bull. 79: 143-150.

Received 6.6.1985

Accepted 12.2.1986 